\begin{tabular}{|c|c|c|}
\hline \multirow{3}{*}{$\begin{array}{r}\text { Case Reports in } \\
\text { Gastroenterology }\end{array}$} & \multirow{2}{*}{\multicolumn{2}{|c|}{ Case Rep Gastroenterol 2016;10:352-359 }} \\
\hline & & \\
\hline & $\begin{array}{l}\text { DOI: } 10.1159 / 000447486 \\
\text { Publisnea onilne: July } 8,2016\end{array}$ & $\begin{array}{l}\text { (C) } 2016 \text { The Author(s) } \\
\text { Published by S. Karger AG, Basel } \\
\text { www.karger.com/crg }\end{array}$ \\
\hline & \multicolumn{2}{|c|}{$\begin{array}{l}\text { This article is licensed under the Creative Commons Attribution-NonCommercial } 4.0 \\
\text { International License (CC BY-NC) (http://www.karger.com/Services/OpenAccessLicense). } \\
\text { Usage and distribution for commercial purposes requires written permission. }\end{array}$} \\
\hline
\end{tabular}

\title{
Hyperbilirubinemia without Transaminitis during Combined Therapy with Daclatasvir and Asunaprevir
}

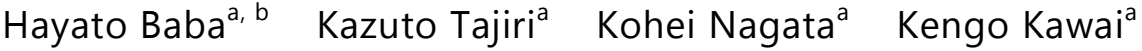 \\ Masami Minemura $^{a}$ Toshiro Sugiyama ${ }^{a}$ \\ ${ }^{a}$ The Third Department of Internal Medicine, Toyama University Hospital, Toyama, Japan; \\ ${ }^{b}$ Department of Education and Clinical Training, Toyama University Hospital, \\ Toyama, Japan
}

\section{Keywords}

Cirrhosis · Direct-acting agent $\cdot$ Hepatitis C virus $\cdot$ P-glycoprotein $\cdot$ Hyperbilirubinemia

\begin{abstract}
Daclatasvir (DCV) and asunaprevir (ASV) are direct-acting antivirals (DAAs) used in the treatment of chronic hepatitis $\mathrm{C}$ virus (HCV) infection. Combined therapy with DCV and ASV shows high efficacy and safety even in patients with cirrhosis. We encountered a patient exhibiting severe hyperbilirubinemia during combined therapy, which is an unreported side effect of DCV and ASV. A 78-year-old woman with cirrhosis developed hyperbilirubinemia $>10 \mathrm{mg} / \mathrm{dl}$ without transaminitis 3 weeks after starting combined therapy. We suspected DAAs-induced liver disorder and discontinued treatment, which resulted in the improvement of hyperbilirubinemia. Caution is required in the use of DAAs for patients with advanced cirrhosis.




\section{Introduction}

Chronic hepatitis C virus (HCV) infection affects an estimated 130-150 million people worldwide, and is a substantial global health problem [1]. HCV infection has generally been treated with pegylated interferon- $\alpha /$ ribavirin. However, treatment regimens containing pegylated interferon have been problematic for patients with cirrhosis because of reduced response rates and more frequent and severe adverse events [2-5].

Direct-acting antivirals (DAAs) have been developed as alternative treatments due to their efficacy and safety. The oral combination of daclatasvir (DCV) and asunaprevir (ASV) is an interferon-free regimen consisting of DAAs, and shows high efficacy and safety even in patients with compensated cirrhosis [6,7]. This DCV+ASV regimen was first available as interferon-free treatment for HCV infection in daily practice in Japan, earlier than in other countries. The main adverse event of DCV+ASV treatment is transaminitis, and elevation of alanine aminotransferase (ALT) and aspartate aminotransferase (AST) levels were reported in $17.6 \%$ and $14.1 \%$ of cases in phase 2 and phase 3 trials conducted in Japan, respectively [6]. In contrast, hyperbilirubinemia was reported in $3.9 \%$ of patients. However, severe hyperbilirubinemia over Grade 3 was reported in only $0.8 \%$ of cases, and hyperbilirubinemia followed transaminitis in these cases [6].

We encountered a patient exhibiting hyperbilirubinemia $>10 \mathrm{mg} / \mathrm{dl}$ without transaminitis during combined DCV+ASV therapy. The clinical course and results of histopathological analysis suggested dysfunction of hepatocytic transporters causing severe bilirubinemia and liver failure. We report this case, which highlights the need for caution in use of DAAs for patients with compensated cirrhosis who may have hepatocytic transporter hypofunction.

\section{Case Report}

A Japanese woman had been found to have liver dysfunction and was diagnosed with chronic hepatitis $\mathrm{C}$ in her 40s. As she had depressive episodes, she could not receive treatment using interferon. As she had paroxysmal atrial fibrillation and showed arterial thrombosis in her lower leg, she had been treated with warfarin since 75 years old. At 78 years old, she was found to have hepatocellular carcinoma (HCC), and was treated with radiofrequency ablation (RFA). After successful treatment with RFA, there was no recurrence of HCC. Although she was 79 years old, administration of DAAs was considered suitable to preserve liver function and suppress the recurrence of HCC. The laboratory data at the start of therapy are shown in table 1 . Although liver biopsy had not been done, the laboratory data suggested that she had liver cirrhosis, and Child-Pugh score was 6. Her HCV genotype was Ib and serum HCV-RNA was $6.5 \mathrm{log}$ copies/ml. NS5A resistance-associated variants (at positions L31 or Y93) were not detected. Therefore, DCV (60 mg once daily) and ASV (100 mg twice daily) were introduced. There were no significant changes in laboratory data at 14 days after commencement of DCV+ASV treatment. Her HCV-RNA level was markedly decreased to $1.76 \log$ copies/ml at 14 days after commencement of DCV+ASV administration.

At 18 days, she developed fever $>38^{\circ} \mathrm{C}$. The fever did not abate, and she was admitted to our hospital at 21 days after introduction of DCV+ASV. The laboratory data on admission are shown in table 1. ALT and AST were not elevated, but bilirubin, predominantly direct bilirubin, showed marked elevation. Prothrombin time was prolonged from $83 \%$ before to $<10 \%$ after introduction of combined DAA treatment. In addition, inflammatory markers, such as white blood cell counts and C-reactive protein, were elevated. Although physical findings 


\section{Case Reports in Gastroenterology}

Case Rep Gastroenterol 2016;10:352-359 $10.1159 / 000447486$ www.karger.com/crg

Baba et al: Hyperbilirubinemia without Transaminitis during Combined Therapy with Daclatasvir and Asunaprevir

suggesting hepatic encephalopathy were not observed, abdominal ultrasound showed mild ascites, which was not recognized before introduction of DAAs treatment. Therefore, ChildPugh score became 12. On computed tomography (CT) examination, no obvious obstruction in the biliary tract was found, but infiltrative shadow and pleural fluid in the left lung were recognized (fig. 1). Although we performed blood and sputum culture on admission, the causative agent could not be detected. However, inflammatory responses in laboratory data and findings from CT suggested bacterial pneumonia accompanying DAAs treatment. The absence of obvious obstruction in the biliary tract and transaminitis suggested that jaundice was caused by dysfunction of hepatocytes. As jaundice occurred after the introduction of DCV+ASV treatment, it was most likely induced by DAAs; therefore, we decided to stop administration and observe the process. Treatment for pneumonia was begun with ampicillin/sulbactam (AMPC/SBT) at $6 \mathrm{~g} /$ day.

We showed the clinical course (fig. 2). After cessation of DCV+ASV treatment, the serum level of bilirubin was elevated to $15 \mathrm{mg} / \mathrm{dl}$, peaked at 3 days after admission, and subsequently decreased. Fever and inflammatory responses in laboratory data also improved, and administration of AMPC/SBT was ended at 8 days after admission. Eosinophilia was also recognized on admission, and the eosinophil count increased to $860 / \mu \mathrm{l}$, peaking at 4 days after admission. The drug-induced lymphocyte stimulation test (D-LST) was also performed at 3 days after admission. As a result, stimulation index of DCV and ASV were 261 and 240\% respectively whereas control stimulation index was $170 \%$, which showed both drugs were positive for D-LST. These results, such as eosinophilia and positive for D-LST, suggested that DAAs-induced hypersensitivity might be found. To assess the causes of hyperbilirubinemia and histopathological changes in the liver, we conducted a liver biopsy at 17 days after admission (fig. 3). Chronic moderate to severe interface hepatitis and fibrosis with bridging pattern were observed, compatible with HCV-induced cirrhosis. Infiltrating cells were mainly lymphocytes, and few eosinophils and neutrophils were observed. Bile ducts in the portal area were preserved, and chronic nonsuppurative destructive cholangitis was not observed. In addition, cholestasis was not remarkable. These findings suggested that temporary druginduced cholestatic liver injury was accompanied with HCV-cirrhosis and hyperbilirubinemia was induced.

The patient made steady progress, and was discharged at 21 days after admission. After discharge from the hospital, there has been no exacerbation of liver failure. Although DCV and ASV were not administered after cessation of treatment, HCV-RNA became negative at 4 weeks after the introduction of DAAs (at 7 days after admission). Then the sustained virological response at 12 weeks (SVR12) was confirmed (table 1).

\section{Discussion}

The all-oral combination of DCV and ASV is an interferon-free regimen consisting of DAAs, and shows high efficacy and safety even in patients with compensated cirrhosis $[6,7]$. Although one advantage of the combination of these two drugs is applicability in patients with compensated cirrhosis, we encountered a patient turning from compensated to decompensated cirrhosis exhibiting severe hyperbilirubinemia during combined therapy.

The most common adverse events $(\geq 10 \%)$ were reported to be nasopharyngitis, increased ALT and AST, headache, and pyrexia headache, in Japanese phase 3 study [6], and fatigue, diarrhoea, nausea, and asthenia in multinational phase 3 study [7]. On the other hand, ALT and AST elevations were the most frequent adverse events over Grade 3 and were 


\section{Case Reports in \\ Gastroenterology}

Case Rep Gastroenterol 2016;10:352-359 $10.1159 / 000447486$

C 2016 The Author(s). Published by S. Karger AG, Basel www.karger.com/crg

Baba et al.: Hyperbilirubinemia without Transaminitis during Combined Therapy with Daclatasvir and Asunaprevir

the most frequent cause of discontinuation in both trials [6, 7]. Although hyperbilirubinemia has been reported, hyperbilirubinemia over grade 3 was rare [6, 7]. In addition, hyperbilirubinemia over Grade 3 reported in these trials accompanied transaminitis [6]. Thus, grade 3 hyperbilirubinemia without transaminitis has not been reported previously.

The clinical course in this case strongly suggested that combined DCV+ASV therapy caused aggravation of liver function with severe jaundice. We postulated two possible causes of severe hyperbilirubinemia in this case with advanced cirrhosis. The first was allergyinduced hyperbilirubinemia, which was suggested by the temporary increase in number of eosinophils in the blood and the result of D-LST. However, the discrepancy of severity between hyperbilirubinemia and eosinophilia and atypical histology for allergic liver injury indicated that an allergic mechanism can explain only part of this pathology.

The second possibility was impairment of hepatocyte transporters by DAAs. DAAs, including DCV and ASV, are metabolized via hepatocyte transporters, such as organic aniontransporting polypeptide (OATP) and P-glycoprotein (P-gp) [8]. Especially, DCV and ASV are known to be substrates and inhibitors of P-gp expressed in hepatocytes, which is involved in bilirubin transport. The expression of P-gp was reported to decrease with progression of liver fibrosis in chronic hepatitis C patients $[9,10]$. Moreover, cholestasis often occurs through inhibition of canalicular excretion of conjugated bilirubin by proinflammatory cytokines in cases of systemic infection, such as pneumonia [11]. Indeed, jaundice was observed in $3-25 \%$ of patients with pneumococcal pneumonia [12]. In this case, cholestasis could occur because the function of P-gp, expression of which was originally decreased with the progression of chronic hepatitis, was impaired by administration of DAAs and the onset of pneumonia. Thus transporter dysfunction may explain hyperbilirubinemia without transaminitis in this case. The elevated concentrations of DCV and ASV caused temporary dysfunction of hepatocytes, and the function recovered with gradual decreases in concentration. A recent study showed that hypoalbuminemia was also associated with increases in ASV concentration [13]. The SVR12 with administration of DAAs for only 3 weeks may have been related to the high concentrations of DAAs used in this case.

Liver histology in this case was compatible with HCV-induced cirrhosis. Although there was discrepancy between serum HCV-RNA level and liver histology, previous studies found no correlation between histology and the extent of replicative activity of HCV [14]. Considered with the absence of new parenchymal inflammation and bile duct obstruction, there was a high possibility that temporary dysfunction of hepatocytes had been occurred.

The treatment of HCV infection with DAAs is highly effective, and these regimens will likely be widely adopted over the next 20 years, which would result in HCV infection becoming a rare disease [15]. On the other hand, severe adverse events may occur in patients with compensated cirrhosis like this case. Although the examination of hepatic function once every two weeks is encouraged during first 12 weeks from administration, more frequent examinations are desirable for high-risk cases in terms of the prevention of severe side effects.

In conclusion, we encountered a patient exhibiting severe hyperbilirubinemia without transaminitis during combined DCV+ASV therapy. Impairment of hepatocyte transporters by DAAs may cause hyperbilirubinemia. Caution is needed with regard to use of DAAs in patients with compensated cirrhosis.

\section{Ethical Statement}

The authors have no ethical conflicts to disclose. 


\section{Case Reports in \\ Gastroenterology}

\section{Disclosure Statement}

All authors declare no conflict of interest related to the manuscript.

\section{References}

1 World Health Organization. Hepatitis C key facts. WHO factsheet No 164. April, 2014.

Http://www.who.int/mediacentre/factsheets/fs164/en/ (Accessed December 29, 2015).

-2 Poordad F, Bronowicki JP, Gordon SC, et al: SPRINT-2 and RESPOND-2 investigators. Factors that predict response of patients with hepatitis $\mathrm{C}$ virus infection to boceprevir. Gastroenterology 2012;143:608-618.e1, 5.

3 Jacobson IM, Dore GJ, Foster GR, et al: Simeprevir with pegylated interferon alfa 2a plus ribavirin in treatment-naïve patients with chronic hepatitis C virus genotype 1 infection (QUEST-1): a phase 3, randomized, double-blind, placebo-controlled trial. Lancet 2014;384:403-413.

4 Hézode C, Fontaine H, Dorival C, et al: Effectiveness of telaprevir or boceprevir in treatmentexperienced patients with HCV genotype 1 infection and cirrhosis. Gastroenterology 2014;147:132142.e4.

-5 Bruno S, Shiffman ML, Roberts SK, et al: Efficacy and safety of peginterferon alfa-2a (40KD) plus ribavirin in hepatitis C patients with advanced fibrosis and cirrhosis. Hepatology 2010;51:388-397.

-6 Kumada H, Suzuki Y, Ikeda K, et al: Daclatasvir plus asunaprevir for chronic HCV genotype 1b infection. Hepatology 2014;59:2083-2091.

7 Manns M, Pol S, Jacobson IM, et al: All-oral daclatasvir plus asunaprevir for hepatitis C virus genotype 1b: a multinational, phase 3, multicohort study. Lancet 2014;384:1597-1605.

8 Hill L: Hepatitis C virus direct-acting antiviral drug interactions and use in renal and hepatic impairment. Top Antivir Med 2015;23:92-96.

-9 Nakai K, Tanaka H, Hanada K, et al: Decreased expression of cytochromes P450 1A2, 2E1, and 3A4 and drug transporters $\mathrm{Na}$--taurocholate-cotransporting polypeptide, organic cation transporter 1 , and organic anion-transporting peptide-C correlates with the progression of liver fibrosis in chronic hepatitis C patients. Drug Metab Dispos 2008;36:1786-1793.

10 Hanada K, Nakai K, Tanaka H, et al: Effect of nuclear receptor downregulation on hepatic expression of cytochrome P450 and transporters in chronic hepatitis C in association with fibrosis development. Drug Metab Pharmacokinet 2012;27:301-306.

11 Minemura M, Tajiri K, Shimizu Y: Liver involvement in systemic infection. World J Hepatol 2014;6:632642.

12 Radford AJ, Rhodes FA: The association of jaundice with lobar pneumonia in the territory of Papua and New Guinea. Med J Aust 1967;2:678-681.

13 Akuta N, Sezaki H, Suzuki F, et al: Relationships between serum asunaprevir concentration and alanine aminotransferase elevation during daclatasvir plus asunaprevir for chronic HCV genotype $1 \mathrm{~b}$ infection. J Med Virol 2016;88:506-511.

14 De Moliner L, Pontisso P, De Salvo GL, et al: Serum and liver HCV RNA levels in patients with chronic hepatitis C: correlation with clinical and histological features. Gut 1998;42:856-860.

15 Kabiri M, Jazwinsli AB, Roberts MS, et al: The changing burden of hepatitis C in the United States: model-based predictions. Ann Intern Med 2014;161:170-180. 

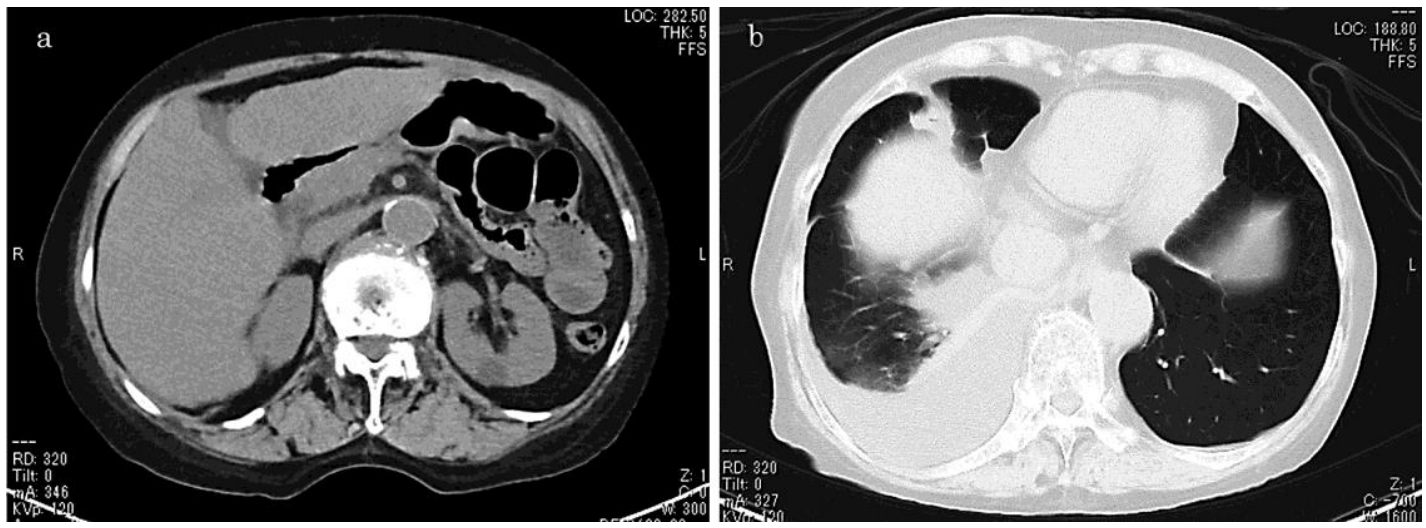

Fig. 1. CT on admission. a Although the surface and edge of the liver were dull due to cirrhosis, obvious obstruction in the biliary tract was not found. $\mathbf{b}$ Infiltrative shadow and pleural fluid in the left lung were observed.

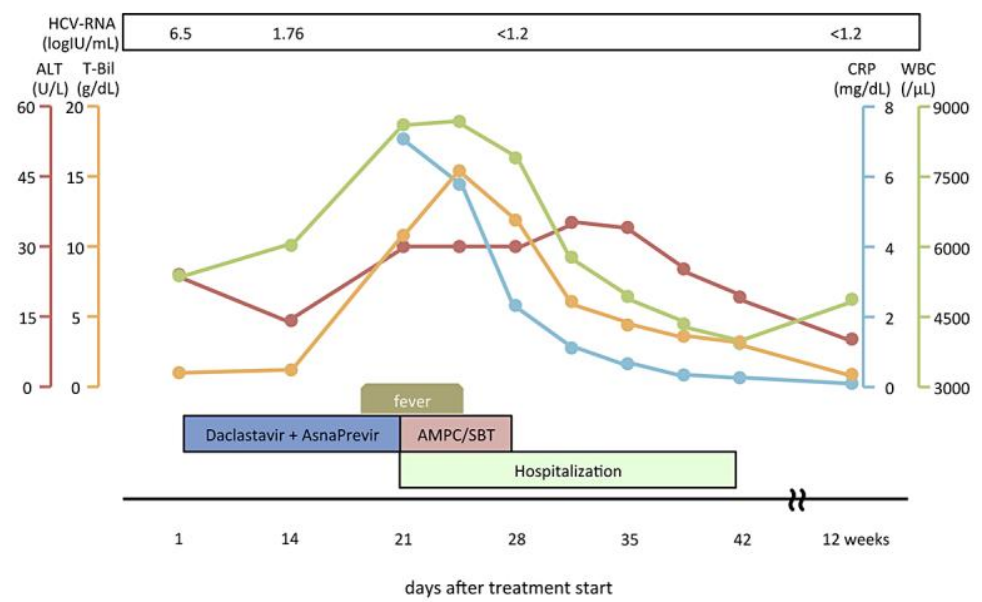

Fig. 2. Clinical course of this case. 


\section{Case Reports in Gastroenterology}
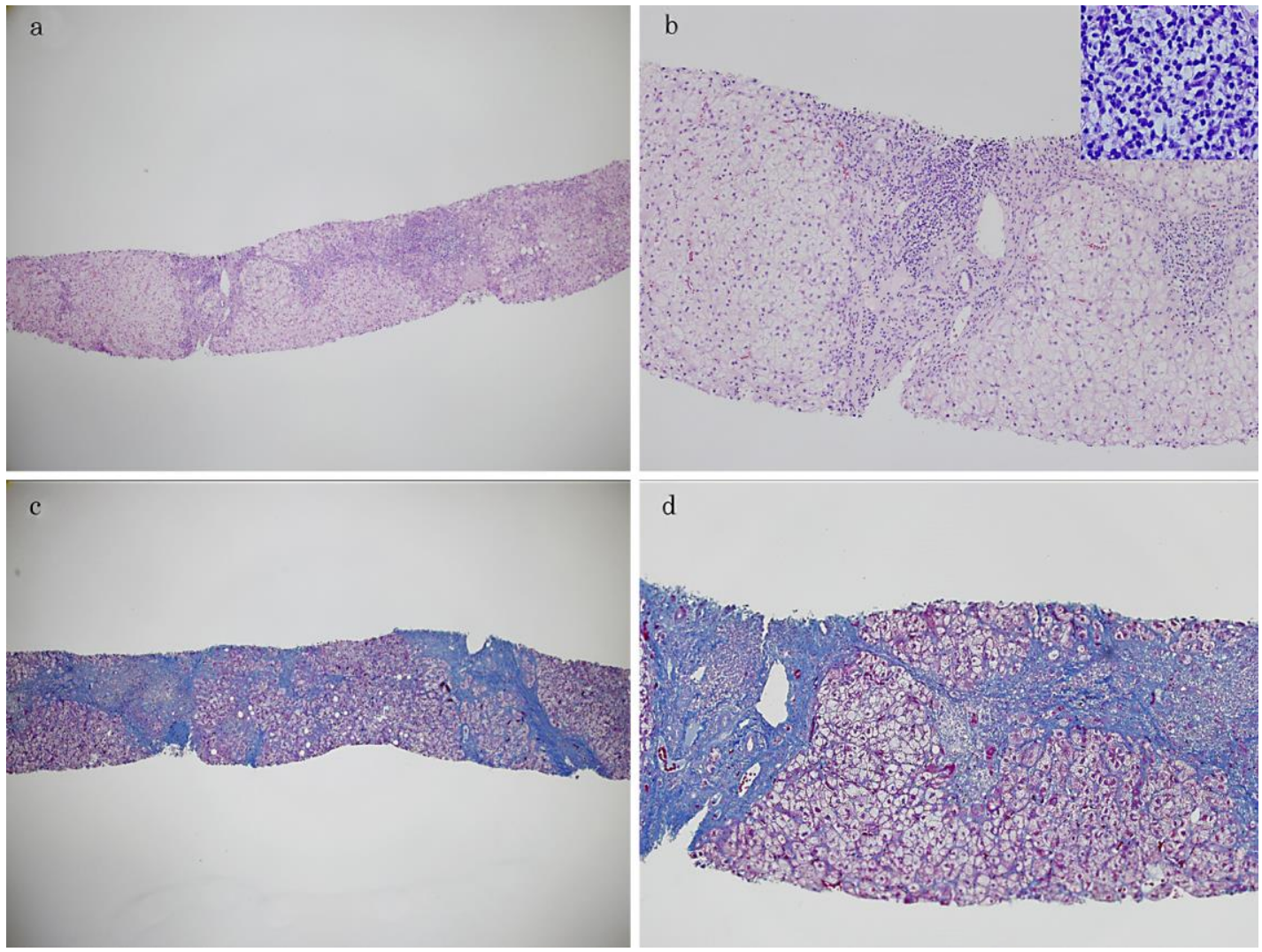

Fig. 3. Liver histology. a Inflammation was mainly located in portal areas, and parenchymal inflammation was mild. The grade was A2 according to the New Inuyama Classification. b Marked ballooning of hepatocytes was observed, but no bile duct injury was found. Infiltrating cells were mainly lymphocytes, and few eosinophils and neutrophils were observed. c, d Severe fibrosis was recognized, and the stage was F4 according to the New Inuyama Classification. a H and E, $\times 40$. b H and E, $\times 100$ and $\times 400$ (small window, upper left column). c Azan, ×40. d Azan, ×100. 


\section{Case Reports in Gastroenterology}

Case Rep Gastroenterol 2016;10:352-359

c 2016 The Author(s). Published by S. Karger AG, Basel www.karger.com/crg

Baba et al.: Hyperbilirubinemia without Transaminitis during Combined Therapy with Daclatasvir and Asunaprevir

Table 1. Laboratory data

\begin{tabular}{|c|c|c|c|}
\hline & $\begin{array}{l}\text { Before } \\
\text { treatment }\end{array}$ & $\begin{array}{l}\text { On admis- } \\
\text { sion }\end{array}$ & $\begin{array}{l}\text { At } 12 \text { weeks } \\
\text { after treat- } \\
\text { ment }\end{array}$ \\
\hline \multicolumn{4}{|l|}{ Blood cells } \\
\hline Red blood cell, $\times 10^{6} / \mu \mathrm{l}$ & 4.4 & 4.3 & 4.2 \\
\hline Hemoglobin, g/dl & 14.5 & 13.6 & 13.5 \\
\hline Hematocrit, \% & 0.4 & 0.4 & 0.4 \\
\hline White blood cell, $\mu \mathrm{l}$ & 4,070 & 8,600 & 4,870 \\
\hline Neutrophils, \% & 50.5 & 68.0 & 46.7 \\
\hline Lymphocytes, \% & 42.0 & 10.0 & 47.2 \\
\hline Monocytes, \% & 6.6 & 9.0 & 5.5 \\
\hline Eosinophils, \% & 0.2 & 7.0 & 0.2 \\
\hline Basophils, \% & 0.7 & 1.0 & 0.4 \\
\hline Platelets, $\times 10^{4} / \mu \mathrm{l}$ & 10.1 & 9.6 & 8.9 \\
\hline \multicolumn{4}{|l|}{ Blood chemistry } \\
\hline Aspartate aminotransferase, IU/l & 60 & 47 & 30 \\
\hline Alanine aminotransferase, IU/l & 28 & 30 & 10 \\
\hline Lactate dehydrogenase, IU/l & 163 & 126 & 179 \\
\hline Alkaline phosphatase, IU/l & 417 & 344 & 373 \\
\hline$\gamma$-Glutamyl transpeptidase, IU/l & 29 & 58 & 18 \\
\hline Cholinesterase, IU/l & 110 & 48 & 130 \\
\hline Total bilirubin, mg/dl & 1.0 & 10.8 & 0.9 \\
\hline Direct bilirubin, mg/dl & 0.6 & 8.5 & 0.5 \\
\hline Blood urea nitrogen, $\mathrm{mg} / \mathrm{dl}$ & 17.0 & 35.0 & 17.0 \\
\hline Creatinine, mg/dl & 0.7 & 1.5 & 0.7 \\
\hline Total protein, g/dl & 7.7 & 6.7 & 7.9 \\
\hline Albumin, g/dl & 3.3 & 2.4 & 3.6 \\
\hline C-reactive protein, $\mathrm{mg} / \mathrm{dl}$ & - & 8.1 & 0.1 \\
\hline Ammonia, $\mu \mathrm{g} / \mathrm{dl}$ & 26 & 30 & 22 \\
\hline \multicolumn{4}{|l|}{ Coagulation studies } \\
\hline PT, \% & 0.8 & $<10$ & $49 \mathrm{a}$ \\
\hline PT, INR & 1.1 & 12.2 & $1.39 \mathrm{a}$ \\
\hline \multicolumn{4}{|l|}{ Serological tests } \\
\hline HCV-RNA, logIU/ml & 6.5 & - & not detected \\
\hline Type 4 collagen, ng/ml & 7.9 & - & - \\
\hline Hyaluronic acid, ng/ml & 258.0 & - & - \\
\hline
\end{tabular}

